\title{
The growth and management of R\&D outsourcing: evidence from UK pharmaceuticals
}

\author{
Jeremy Howells, Dimitri Gagliardi and \\ Khaleel Malik
}

Manchester Institute of Innovation Research, Manchester Business School, University of Manchester, Manchester, UK. jeremy.howells@mbs.ac.uk; dimitri.gagliardi@mbs.ac.uk; khaleel.malik@mbs.ac.uk

\begin{abstract}
Outsourcing of research and development (R\&D) activities has become a major management issue for R\&D and technical managers within firms. It has also been of growing concern to academics who are trying to chart the implications of the increasingly distributed nature of research and innovative activities in advanced economies. This study is based on a survey of research-based pharmaceutical companies operating in the United Kingdom conducted in 2004-2006. The aim of this paper is to outline the main reasons for pharmaceutical firms to outsource $R \& D$ and the management practices followed by such companies in relation to outsourcing. The research results provide interesting findings in relation to, for example, the reasons behind outsourcing, the decision-making processes behind such practices and barriers to outsourcing arrangements. These issues are evaluated together with the characteristics of the firms and the specific project outsourced.
\end{abstract}

\section{Introduction}

$\mathrm{O}$ utsourcing of research and development (R\&D) activities has become a major management issue for research and technical managers within firms. This study explores the external sourcing of $R \& D$ and technology in relation to the pharmaceutical industry, which has steadily expanded over the last decade (Jones, 2000). This is evident both in more traditional forms of international linkage, for example, in the growth of technological cooperation alliances (Arora and Gambardella, 1990; Hagedoorn, 1993; Whittaker and Bower, 1994; Howells and Neary, 1995), as well as in newer forms, such as outsourcing of clinical trial work overseas. As such, the research and knowledge boundaries of the firm are becoming more open, porous and indistinct. Above all, the increasingly distributed nature of innovation within the pharmaceutical industry should be seen in an increasingly international context. This is, however, not necessarily a new phenomenon in relation to the pharmaceutical industry (see, e.g., Sanderson, 1972; Liebenau, 1984), but what is new is its nature and extent. R\&D outsourcing appears to be growing rapidly in certain areas, but what is less certain and relatively unexplored are the specific factors behind such growth and the managerial implications for such developments. It is these aspects of $R \& D$ outsourcing that form the main focus of the paper, which it explores in relation to the pharmaceutical industry.

\section{The distinctive nature of $R \& D$ outsourcing}

Although there are a number of generic issues and strategies that firms need to be aware of in 
relation to outsourcing, outsourcing associated with $R \& D$ and innovative activity has a number of peculiarities (Howells, 2006, pp. 63-65). Sourcing knowledge, research and technology inputs externally is different from other types of outsourcing activities in a number of ways:

(1) There are high levels of risk and uncertainty associated with the outcome of research outsourcing (Doctor et al., 2001).

(2) The issue of prior disclosure and information asymmetry, about quality inherent in the market transfer of information, are an essential feature of research and innovation outsourcing in that the client organisation cannot determine the quality of the knowledge they receive unless the prior holder discloses it already (Arrow, 1962).

(3) However, more especially the supplier of the knowledge often does not know the quality of the knowledge it sells in long-term research projects because they themselves do not know, a priori, the future outcomes of their work. This characteristic, in turn, highlights the contractual incompleteness problem in relation to intellectual property exchange involved, where it is not possible to stipulate exhaustively the appropriate conditional responses in a research contract.

(4) Another distinctive key feature of research and technology outsourcing is that both the producer and the consumer are involved, at least to some extent, in the co-joint production of new knowledge (Alchian and Demsetz, 1972), leading to intellectual property rentsharing issues.

(5) Related to this, there are also a whole set of related moral hazard problems: (a) in that client organisation can use the existing knowledge in a manner that is not easily observable by the supplier (de Laat, 1999, p. 209); (b) in that the supplier can use the existing knowledge provided to the recipient to other potential partners and that is not easily observable by the client organisation; and (c) in that the supplier can use co-produced knowledge, generated in conjunction with the recipient, and supply it (intentionally or unintentionally) to another client organisation.

(6) The central importance of research and technology in forming part of the core competencies and capabilities of the firm (Ford and Farmer, 1986); getting R\&D outsourcing wrong can have a major impact on the longterm future of the firm.
(7) The often irreversible nature of the outsourcing decision in terms of its effect on $R \& D$ or technical capacity, at least over the short and medium term (see Welch and Nayak, 1992).

(8) Each exchange of information associated with knowledge and research is essentially a unique event, and is therefore not like other transactions that are repeatable in the nature of what is exchanged (Carter, 1989, p. 157). Learning about the R\&D outsourcing process is therefore more limited in nature.

(9) Much of the know-how exchanged in the outsourcing process is often highly tacit in nature (Howells, 1996; Cavusgil et al., 2003) and is therefore more difficult to control or formally administer within a contract.

Some of these features and issues can be seen in other outsourcing activities, particularly associated with other knowledge-intensive collaborations and transactions related to IT projects. However, the interlinked nature of the issues described above, together with the dominant features of a high knowledge component, combined with the unknown outcomes of many R\&D activities involved in the transaction, means that outsourcing for innovation has particularly distinctive features. The issue of the 'unknown' is crucial here, because so much of the outcomes of research and other forms of innovation outsourcing is uncertain and this colours all aspects of the sourcing relationship. The issue of the prior disclosure problem associated with knowledge exchange is well known and has long been reiterated in relation to $R \& D$ outsourcing, but this is about the exchange of existing knowledge. The exchange of existing technological knowledge in relation to technology licensing is extremely important (Lowe and Taylor, 1998, p. 264), but the whole process of exchange or sourcing becomes even more complex when we discuss the issue in relation to new knowledge. Here, both the receiver and the supplier do not know the final quality of the knowledge they are exchanging (point 5(c)).

\section{Research and innovation in pharmaceuticals: an evolving industry}

To provide some context to pharmaceutical outsourcing and collaboration, it is necessary to outline briefly the dynamics of research and innovation within the industry. The pharmaceutical industry is a high-value research-intensive sector that competes on the quality and efficacy 
of the new products it generates and has strong links to the science base. As such, innovation is a key competitive weapon and represents a core competence for the firm (Prahalad and Hamel, 1990). In turn, the management of knowledge activity associated with the innovation process is critical for long-term success. The industry relies heavily on intellectual property rights to protect the large sums invested in the risky venture of new drug developments and the proprietary knowledge that they are based on. However, pharmaceutical companies face continuing pressures from rising $R \& D$ costs and depreciating value of patents, as patent life is eroded by testing procedures, and pressures from public authorities to cut health care costs. In particular, clinical trial costs are becoming ever more important in the overall cost structure of drug development. Thus, between 1994-1995 and 1998-2001, it is estimated that annual growth in clinical trial sizes in the United States grew by $7.47 \%$ per year (DiMasi et al., 2003, p. 177) and it is estimated that by 2004, US drug companies were spending as much as $37 \%$ of their total R\&D budgets on clinical trial activity. ${ }^{1}$ To counter this, companies have sought to make time savings elsewhere in the $R \& D$ process, with the automation and associated miniaturisation of the drug-screening process yielding major productivity improvements and time savings (Nightingale, 2000).

The pharmaceutical industry has undergone a profound change with the rise of new researchbased biotechnology and biopharmaceutical firms that have entered the drug market since the late 1970s (see, e.g., Shan et al., 1994; Walsh et al., 1995; Powell et al., 1996; Powell, 1998). This has been associated with the application of new bodies of knowledge, in such areas as cell and molecular biology, pharmacology and physiology, in the pharmaceutical industry (Orsenigo, 1989; Della Valle and Gambardella, 1993; McKelvey, 1995), and these were fields where large, established pharmaceutical firms, based on traditional chemistry, lacked experience. Such discontinuities created the potential for certain firms to improve their competitive and network position (Madhavan et al., 1998, p. 445). It was recognised that the previously dominant firms, the established pharmaceutical companies, were having difficulty in adapting to this new paradigm while the new biotechnology-based firms (NBFs) were seizing these opportunities to exploit such discontinuities.

The emergence and growth of the NBFs has, however, not been easy as they have been con- fronted with high entry barriers associated with the high costs of development and marketing, which remain prohibitive, and the problem that regulatory expertise and marketing competence specific to national markets cannot be acquired easily. ${ }^{2}$ Equally, large pharmaceutical companies have been seeking to become more flexible and faster to market via partnerships with these smaller biotechnology firms (Pisano et al., 1988; Pisano, 1994) and have been able to absorb this 'new' knowledge by interacting with these new entrants (Orsenigo et al., 2001) to boost innovation. In these new entrants to the pharmaceutical industry in the from of NBFs, there have emerged further sets of what Orsenigo et al. (2001, p. 501) define as 'specialist' firms (as compared with more 'generalist firms'), namely specialist contract research organisations (CROs), especially centred on clinical trial and testing work; service companies specialising in genomic information and research services (Mittra, 2003); and knowledge management system firms providing bespoke service to the pharmaceutical sector (Studt, 2003). The complementarities and links between the large generalists and smaller specialist firms, such as Chemical Design and Oxford Molecular in the United Kingdom, have grown so that these new entrants have become key partners and intermediaries in the drug-discovery process.

How is the pharmaceutical industry therefore defined for the purposes of this study? The pharmaceutical industry in the United Kingdom is classified in a narrow, manufacturing sense, and may be seen as its traditional, first layer of the industry [in the United Kingdom, this is classified under the Standard Industrial Classification (SIC) 24.41 and 24.42 categories (UK SIC, 2003), but excluding SIC subsectors 24.4 .3 and 4]. However, in the modern industry we should also consider adding a new set of layers to this one. These include those involved in the newer biological sciences (in particular, NBFs involved in pharmaceutical research), plus contract research, development and clinical trial companies and these will mainly be classified under R\&D services (SIC classification 73.10; because they do not undertake any manufacturing). However, with the revolution in the information sciences as applied to the pharmaceutical industry and genomics in particular, we also need to consider a further set of service companies involved in genomic information and research services for the pharmaceutical industry (Groenewegen and Wouters, 2004). Such companies are mainly found under UK SIC (2003) codes of software consultancy and supply 


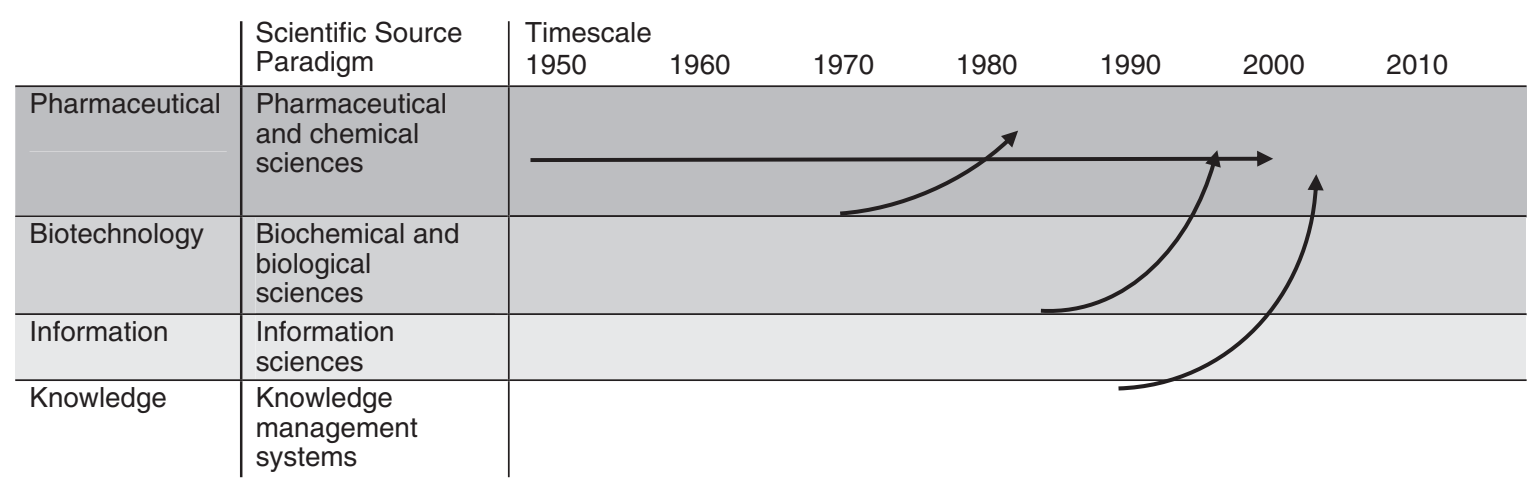

Figure 1. New scientific regimes in the pharmaceutical industry.

(SIC 72.20), data processing (SIC 72.30) and/or database activities (SIC 72.40) and these form the third and fourth paradigmatic layers of the new pharmaceutical industry 'major' (Figure 1). Some firms, such as Oxford Molecular, with its drug discovery and software solutions divisions, can span two or three layers. Indeed, knowledge management systems could potentially form the latest, new paradigm realm to the industry (Studt, 2003), promising to provide better integration of the other three layers. However, the promise of knowledge management systems providing a seamless and integrative solution to the industry still appears to be a long way off (Howells, 2002).

The evolution of the industry can be seen as a series of accretions (or rings): a traditional first layer (or 'inner core') based on established chemical sciences that formed the dominant paradigm up until the 1970s (Liebenau, 1984); a second layer (Orsenigo et al., 2001, p. 498) associated with the rise of biotechnology and the growing importance of biological sciences, particularly molecular biology (Orsenigo, 1989; Della Valle and Gambardella, 1993; McKelvey, 1995); a third layer (or 'new periphery') associated with information sciences, particularly those centred around genomics (Groenewegen and Wouters, 2004; see also Mittra, 2003); and a potential fourth layer centred around knowledge management systems (Studt, 2003). These layers can be seen as forming some kind of historical accretion and transition and indicate issues of power dependency (with the first layer or 'inner core' still dominating and controlling the crucial drug development and marketing process; Orsenigo et al., 2001), although increasingly interpenetrated and permeable and in some sense breaking down. Thus, the project-level adoption of new combinatorial chemistry and high-throughput technologies raises fundamental challenges to the role of chemists in the traditional inner core of the industry (Thomke and Kuemmerle, 2002, p. 631). Power-dependent relations, based on both scientific and financial resources, are continuing to evolve and change, with potentially further rings being added to the industry structure.

This evolving model of the industry is important in highlighting the various scientific 'source' paradigms impacting on the sector (Galambos and Sturchio, 1996). However, they are significant for another reason. It is also important to recognise that the boundaries of the pharmaceutical industry are also subject to evolutionary change and permeability. By taking too traditional and static a view of the industry (e.g., by concentrating on only certain patent classes relating to the industry), we may miss important developments on the 'industry major', which could be of increasing significance. We need to acknowledge the dynamic and evolutionary development of industries just as much as the innovation processes that are associated with their change. The boundaries of the industry are continually shifting and changing and becoming more permeable. The current industry scenario, therefore, presents an evolving and hierarchical industry structure of small specialist firms (biotechnology, CROs, genomic and knowledge management firms), on the one hand, surrounding the large generalist pharmaceutical companies, on the other. The complementarities and links between the large generalists and smaller specialist firms have grown so that these new entrants have become key (although still subordinate) partners in the drug-discovery process.

\section{Research methodology and survey framework}

The study is based on a survey of pharmaceutical enterprises in the United Kingdom. ${ }^{3}$ On the basis of the earlier discussion about the industry, the 
study was based on a questionnaire survey of the pharmaceutical industry, focusing on those enterprises that undertake $\mathrm{R} \& \mathrm{D}$ activity. It therefore involved a survey of pharmaceutical manufacturing enterprises (prescription, over-thecounter and generic products) as well as related biotechnology and research organisations that undertake pharmaceutical research, and a small, but growing, number of specialist pharmaceutical information science companies. Thus, enterprises associated with the whole innovation value chain of the pharmaceutical industry were identified and selected for study. The survey therefore targeted the pharmaceutical industry as defined within SIC 24.4.1 (manufacture of basic pharmaceutical products) and SIC 24.4.2 (manufacture of pharmaceutical preparations), but also included other groups of firms that formed part of the wider pharmaceutical industry fabric covering: SIC 73.10 (research and experimental development on natural sciences and engineering), SIC 72.2 (software consultancy and supply) and SIC 72.3 (data processing; Appendix A, Table A1).

The initial population list of some 1,000 business units was derived using Office for National Statistics and commercial databases. Some 233 enterprises in our database [200 from the SIC 24.4 group (manufacture of pharmaceutical preparations) and 33 from the SIC 51.46 group (wholesale of pharmaceutical goods)] were not included in the final population list because they undertook no R\&D activities on a regular basis. From this dataset, 806 businesses or enterprises (independent companies, associate companies, joint ventures, majority owned subsidiaries and wholly owned subsidiaries) were identified as being involved on a regular basis in $R \& D$ activities (Appendix A, Table A1). These business, or enterprise, units form our unit of analysis (although information at a project level has also been gained) and this set constitutes the statistical objective of our analysis.

A pilot survey was undertaken in late 2004 and after changes to the content of the questionnaire, the main phase of the survey ended at the beginning of 2006. In total, the survey received 105 completed questionnaires out of 806 businesses, a response rate of some $13.03 \%$. The survey responses were checked for survey bias with the sampled population and no significant biases were revealed as a Pearson's $\chi^{2}$ test supported the hypothesis that the sample was representative of the population. The sample accounts for over $50 \%$ of the pharmaceutical turnover and employ- ment in the United Kingdom; the sample businesses also account for well over half of the estimated R\&D expenditure in the United Kingdom in 2003 (with these businesses in turn operating some 174 research centres). Of the 105 enterprises surveyed, some $56 \%$ were independent firms.

The questionnaire covers questions relating to the sourcing of $\mathrm{R} \& \mathrm{D}$, technical and knowledge inputs to the enterprise over time (using two datum points: 1998 and 2003). The format of the questionnaire was mainly based on closed questions, although, where applicable, an 'other' category was included, together with the predefined questions, and this allowed the respondent to indicate issues that had not been included in the list. In addition, space was also made available for open-ended responses to be made at the end of the questionnaire. The questionnaire was in three main parts: the first section discussed the size and context of R\&D activity within the enterprise; and the second section focused concentrated on the nature and extent of external research and technical activity by the enterprise; the third main section on asking questions about the most 'significant' R\&D or innovation project an enterprise undertook over the last 3 years. After the pilot survey, it was decided to allow the respondents to make a decision of how they interpreted what was 'significant' out of the following four categories: (a) overall cost of the project; (b) in terms of the firm's core technology base; (c) future expected financial gains from the project; and (d) other reasons that had to be specified.

What did these externally sourced R\&D and technical activities actually cover? They relate to the following functions: basic research; applied research; experimental development; reverse engineering; world market product development; adapting and developing products for the UK market; product design; testing and prototyping; market research and marketing; software used in $\mathrm{R} \& \mathrm{D}$; and clinical trial work. The study also undertook some case-study interviews with biopharmaceutical companies and personalised medicine companies to provide an additional perspective to the study.

\section{R\&D outsourcing in pharmaceuticals}

\subsection{Introduction}

Section 3 has already sought to posit the role of R\&D outsourcing within the wider context of 
Table 1. Research and development (R\&D) outsourcing by number of enterprises and as a proportion of total R\&D expenditure

\begin{tabular}{|c|c|c|}
\hline & 1998 & 2003 \\
\hline $\begin{array}{l}\text { Share of enterprises } \\
\text { outsourcing } R \& D \\
\text { activities }(\%)\end{array}$ & 56.62 & 72.38 \\
\hline $\begin{array}{l}\text { Average share of total R\&D } \\
\text { budget outsourced }(\%)\end{array}$ & 13.78 & 25.76 \\
\hline Total response number & 100 & 105 \\
\hline
\end{tabular}

external innovation relations for pharmaceutical firms. The survey sought to explore a specific set of research issues that concerned the overall extent and nature of external R\&D and knowledge activity; factors behind the decision to outsource R\&D and related activities; issues in terms of partner selection; and barriers that inhibit R\&D outsourcing. Each of these will now be considered in turn.

\subsection{The growth and context of external $R \& D$ activity}

\subsubsection{Growth of external $R \& D$ activity}

In terms of the overall extent of R\&D outsourcing within the industry, of the 105 enterprises that responded to the survey, just less than threequarters $(72.38 \%)$ sourced at least some of their research and knowledge requirements externally in 2003. This compares with the figure for 1998 of some $56.6 \%$. The (mean) share of the total R\&D budget that was spent externally also increased from $13.8 \%$ in 1998 to $25.7 \%$ in 2003 (Table 1).

The growth in R\&D outsourcing is also reflected in the overall ${ }^{4}$ and relative spend in outsourcing. Thus, the percentage of the $\mathrm{R} \& \mathrm{D}$ budget of the enterprise being spent externally increased from some $13.78 \%$ in 1998 to $25.76 \%$ by 2003 , with a growth of some $10 \%$ over 5 years. More firms are sourcing their research and technical requirements, but also their overall level of spend is also increasing dramatically. Given that nearly three-quarters of enterprises have external innovation linkages, this suggests that the industry is a highly open system, forming a complex distributed innovation network (Coombs and Metcalfe, 2002).

\subsubsection{Size and the likelihood to outsource}

There has been considerable discussion about the level of outsourcing being related to firm size. Within the context of this study, however, there
Table 2. Research and development (R\&D) outsourcing by enterprise size

\begin{tabular}{lccr}
\hline Enterprise size* & \multicolumn{2}{l}{$\begin{array}{l}\text { Outsource } \\
\text { R\&D? }\end{array}$} & Total \\
\cline { 2 - 3 } & No & Yes & \\
\hline Small (0-50) & 13 & 31 & 44 \\
Medium (51-250) & 9 & 24 & 33 \\
Large (251+) & 7 & 21 & 28 \\
Total & 29 & 76 & 105 \\
\hline
\end{tabular}

*Numbers of employees - full-time equivalents.

appears to be no difference in propensity to outsourcing $R \& D$ and knowledge activity according to enterprise size (as measured by full-time equivalents; Table 2). Enterprises of all sizes are active in sourcing their research and knowledge requirements externally and there is no statistically significant relationship in terms of the size of the enterprise, based on a simple $\chi^{2}$ analysis. Initial evidence, however, suggests that there is a significant relationship between the level of external R\&D, technical and related knowledge sourcing and the overall R\&D intensity of the business.

\subsubsection{The decision context}

The strategic significance of these external research and innovation linkages is revealed by the fact that over half $(56 \%)$ of the projects in the survey were decided at the company boardroom level and a further $22 \%$ were considered at the Strategic Business Unit level. By contrast, only $18 \%$ were taken by the research or technical director and just $4 \%$ by the individual scientist or technical operator. The mean (average) number of people in undertaking the sourcing decision was 5.3, although the median was 3.00 (the mode was also 3 ) and there were considerable variations (standard deviation 6.895). In terms of the time spent in making the decision, the average time taken was 6.61 months (although the median was 4 and the mode was 6). Again, there was considerable variation around the mean, with a maximum time to come to a decision being 60 months (standard deviation 8.659). There are no data to make comparisons with these decision contexts; thus, is 6 months a long or a short time? What it does suggest is that these decisions are not taken lightly and that they involve complex and lengthy decision-making processes associated with information asymmetry, prior disclosure and moral hazard issues outlined in Section 2. 


\subsection{Factors behind externally sourcing research and knowledge}

The factors behind the decision to source research and related knowledge activities externally are complex and various. In order to help understand the various factors, Table 3 has sought to outline the key factors in the decision to outsource and to group them to a new typology under the following headings:

1. those overall push and pull factors, which actually initiate the decision to outsource termed here 'initiating factors';

2. 'framing factors', which actually shape and delimit the nature and type of activities accessed externally; these, in turn, can be divided between:

Table 3. Factors behind externally sourcing research and knowledge

\begin{tabular}{ll}
\hline $\begin{array}{l}\text { Factor } \\
\text { categories }\end{array}$ & Factors \\
\hline 1. Initiating factors \\
1.1 Cost savings \\
1.2 Time savings \\
1.3 External projects easier to manage \\
1.4 Lack of in-house R\&D and \\
knowledge \\
1.5 Reduces risk and uncertainty \\
2. Framing factors \\
(i) Implementation factors \\
2.1 Degree of uncertainty \\
2.2 Retention of core technological \\
competence \\
2.3 Degree of task modularity \\
2.4 Regulatory constraints \\
2.5 Degree of tacitness \\
2.6 Degree of tacitness \\
2.7 Ability to reabsorb research and \\
knowledge \\
2.8 Leakage of proprietary knowledge \\
and intellectual property
\end{tabular}

R\&D, research and development. (i) 'implementation factors' associated with issues surrounding the operationalisation of the various aspects of the sourcing process and

(ii) 'outcome factors', which determine the outcome and performance of the activities once they are absorbed back into the firm.

In relation to the initiating factors, and in particular that of the cost and time benefits of outsourcing, these have generally been well covered in the literature relating to outsourcing and collaboration, but also more specifically in relation to research and technical outsourcing by the current authors (see, e.g., Howells, 1999; Howells et al., 2003). In relation to what might be seen as three operational level factors, cost, time and ease of management, time and cost indeed emerged as the second and third most important reasons for the decision to source in research and technical activities [as measured by the mean Likert score for each factor from 1 (low) to 5 (high) (Table 4)]. By contrast, ease of managing projects externally was rated as being the least significant factor. However, it was the lack of in-house R\&D and technical expertise factor that was rated most highly in terms of reasons to outsource.

Another factor in the reason to source R\&D externally was the ability to reduce risk and uncertainty, by sharing it with another partner (or set of partners); however, this was only rated sixth among all the issues. In this context, uncertainty and risk reduction could be seen as an initiating factor, which might encourage outsourcing, although it was not rated very highly. Conversely, therefore, some studies have indicated that the higher the level of uncertainty the less the likelihood of outsourcing $R \& D$ and technical activities (see, e.g., Doctor et al., 2001). Part of this discrepancy may lie in the fact that uncertainty and risk vary according to the type of R\&D being undertaken. Some parts of $\mathrm{R} \& \mathrm{D}$, therefore, have high levels of uncertainty and complexity associated with them, such as

Table 4. Reasons for external sourcing of research and technology

\begin{tabular}{|c|c|c|c|c|}
\hline Rank & Reasons for outsourcing & Likert rating (mean) & Standard deviation & $N$ \\
\hline 1 & Access expertise not available in-house & 4.36 & 1.039 & 72 \\
\hline 2 & Reduce development time and time to market & 3.86 & 1.214 & 72 \\
\hline 3 & Reduce development costs & 3.39 & 1.359 & 72 \\
\hline 4 & Support for technology change in processes & 2.93 & 1.250 & 68 \\
\hline 5 & Support for technology change in products & 2.87 & 1.264 & 71 \\
\hline 6 & Share risks and uncertainties & 2.71 & 1.342 & 70 \\
\hline 7 & Easier to manage & 2.42 & 1.297 & 72 \\
\hline 8 & Other (strategic alliance) & 4.00 & - & 1 \\
\hline
\end{tabular}


Jeremy Howells, Dimitri Gagliardi and Khaleel Malik

Table 5. Propensity to source different types of research and development (R\&D) and technical activities

\begin{tabular}{lll}
\hline $\begin{array}{l}\text { Type of R\&D, technical and } \\
\text { knowledge activity } N=101\end{array}$ & $\begin{array}{l}\text { Ratio of firms undertaking } \\
\text { work internally versus } \\
\text { sourcing externally }\end{array}$ & $\begin{array}{l}\text { \% of activities undertaken } \\
\text { in-house (over total } \\
\text { responses per case) }\end{array}$ \\
\hline Basic research & 1.35 & 57.50 \\
Applied research & 1.02 & 50.59 \\
Experimental development & 1.56 & 60.24 \\
Reverse engineering & 1.13 & 52.94 \\
World market product development & 1.88 & 65.33 \\
Adapting/developing products for UK market & 2.81 & 73.77 \\
Product design & 3.14 & 75.44 \\
Testing and prototype work & 1.41 & 58.44 \\
Market research and marketing & 1.33 & 57.61 \\
Software used in R\&D & 0.81 & 44.68 \\
Clinical trial work & 0.61 & 37.33
\end{tabular}

For the first column the lower the ratio, the more likely the activity is sourced externally. The second column has been derived as follows: number of responses in-house over sum of responses in-house + outsourced. As such, it does not break down the data on outsourcing as percentage of the R\&D budget, but describes the propensity of firms to carry out these activities in-house. It is essentially the same as the "ratio of firms undertaking work internally versus sourcing externally", except that the percentage figure is free from a size effect; each ratio is expressed as percentage of the factor, i.e. in-house basic research services over the total phenomenon (in-house and outsourced). The actual response rates vary for each response; however, the composite average $N$ is over 100 as only a few respondents (three to four) left this section completely blank.

basic or fundamental research, while others, such as modification of products and processes or minor technical improvements, do not (Freeman and Soete, 1997). There are also forms of R\&D that have low levels of uncertainty and complexity, where market-mediated contracts can function. By contrast, more complex and uncertain research requirements would preclude marketbased contracts. This is emphasised by Mowery (1984), who noted that the effectiveness of contracts in the provision of research is undermined by the uncertain nature of the research enterprise, the imperfect character of knowledge about a given project and the thin market for specialised research services. These contractual difficulties are likely to be greater for more technically complex, uncertain research projects. ${ }^{5}$ This suggests that externally sourced research and technology would be restricted to these shorter term, simpler, less uncertain technology activities (Section 2). This hypothesis is, in part, borne out by the survey evidence (see later).

Another framing, or constraining, factor that is especially important in the pharmaceutical industry is that of regulatory controls that, although are more important in relation to outsourcing manufacturing, still represent a major issue when making the decision to outsource R\&D (Schein and Williams, 2002). The issue of verification and traceability of research, trial and test results throughout the drug development cycle is very important here (Section 5.5).

It was noted earlier that delimiting all these decisions concerning the sourcing of research and technical knowledge should be seen as framing a firm's technology strategy and, within that, what it sees as its core technological competences. Undertaking research and technological activity in-house, or seeking external sources for it, is all about maintaining the future competitiveness of the company and the future core competencies and capabilities of the firm (Coombs, 1996). In this context, therefore, the more the research or technology in question is seen as being a core competence, the less likely it is to be sourced externally with another firm or organisation. These points emerged mainly from case-study interviews, but are also evident in the 'propensity to outsource' (Table 5) where routine and specialist activities are more likely to be outsourced than 'activities involving knowledge of the own market (i.e. adaptation to own market) or knowledge creation' (e.g., basic research and design).

Other constraining factors in the decision to source externally were the degree of task modularity and knowledge tacitness. In terms of the research or technical activity, task modularity can be defined as how easy or difficult it is for a firm to decompose, or separate out, a particular research or technical task and give it to another firm or organisation to undertake (Mikkola, 2003). Thus, where a research or technical activity's boundary is very indistinct and involves closely interrelated and complex linkages with other research and technologies, outsourcing would be less likely compared with another activity that forms a much more distinct component and where its relationship with other research areas 
or technologies is simple and clear. The degree of tacitness of the knowledge being transferred is also seen as a factor hindering research and technology transfer (Howells, 1996), which may in turn influence the R\&D outsourcing decision. Thus, the less explicit the knowledge is, the more difficult it is to assimilate it (Cohen and Levinthal, 1990, p. 135; see also Nelson and Winter, 1982; Winter, 1987). Clearly, the degree of tacitness is likely to affect the ability to absorb the research process back into the firm. Indeed, absorption issues, such as different research cultures between the two or more organisations involved, can be seen as a more general outcome factor influencing the decision of whether to outsource or not.

This is also true for leakage of proprietary knowledge and intellectual property, associated with moral hazard problems in outsourcing (Section 2), and can also be seen as both an issue when trying to operationalise and outsource a programme but also in terms of how it affects the final outcome and application of the results that may derive from such a project. Unintended leakage or spillovers of knowledge are hard both to measure and control, but they remain an ongoing concern for $\mathrm{R} \& \mathrm{D}$ managers. The typology in Table 3 has therefore sought to provide a framework in which to view issues surrounding the decision of whether to outsource research and technical activities or not. As has been indicated, the categories are not always mutually exclusive, but this framework has proved successful when trying to dissect the reasons for sourcing research and technical activities externally with other firms.

So far, the discussion has centred on externally sourcing research and technical activities in general. However, as the review has suggested (with, e.g., the issue of uncertainty), the propensity to outsource will vary according to the type of R\&D activity or technical function being considered. To explore this issue, therefore, enterprises were asked to indicate their propensity according to various research and technical functions. ${ }^{6}$ The survey reveals substantial differences in the degree of externality between such activities as product design and adapting and developing products for the UK market, where there is a high internal ratio of work, to $\mathrm{R} \& \mathrm{D}$ software and clinical trial work, where there is a high degree of external sourcing of such work (Table 5). Applied research also reveals a relatively high level of external sourcing (1.02; the lower the score, the more it is sourced externally). What is apparent is that for most activities, there is a fairly high level of external sourcing and collaboration (with ratios equal to or below 1.5), apart from adaptation and product work. The types of work, which attract the highest levels of external linkages, are those associated with specialist competences and/or those not seen as being the core competence of the firm concerned. It is noticeable that the activity with the highest ratios of external sourcing, namely clinical trial activity ( 0.61 and only $37.3 \%$ undertaken in-house), is also the one activity within the innovation chain that has risen fastest in cost terms both in absolute and relative terms. It was noted above that clinical costs, as a proportion of total costs, have continued to soar over the last 10 years; while 'discovery (research) and non-clinical work' has increased in absolute terms, it declined proportionally over the time period. Is external sourcing in the field of clinical trial work a simple response to cost pressures? In part, but clinical trial work is an increasingly specialist function that many drug companies see as a non-core competence. Clinical trial firms, such as Premier Research in the United Kingdom, are much more focused than in-house clinical trial divisions in meeting tight deadlines. Thus, through specialisation these CROs are simply better undertaking most mainstream clinical trial work. In addition, by its very nature clinical trial work involves physically working outside the firm in hospitals and other clinical environments.

Can we say more about these specific types of outsourcing activities and reasons for outsourcing? Correlation analysis, using Spearman's rank correlation, suggests that the most significant relationships centre around, on the one hand, the quite specific operational desires of achieving cost and time savings and, on the other, around more applied, technical activities associated with applied and experimental development R\&D, clinical trial work, R\&D software and product design and manipulation work (Table 6). In particular, the most prominent and significant relationships (below 1\% significance level) are between reducing development costs and the activities associated with product design (0.376), R\&D software (0.275) and experimental development work (0.265) and between time reduction factors with clinical trial activities (0.346), experimental development R\&D work (0.345) and applied R\&D (0.256 at the 3\% significance level).

The other significant relationships are between the need to share risk with activities of product design (0.383) and experimental development work (0.282) significant at the $1 \%$ and $2 \%$ levels, respectively. Interestingly, the need to tap 


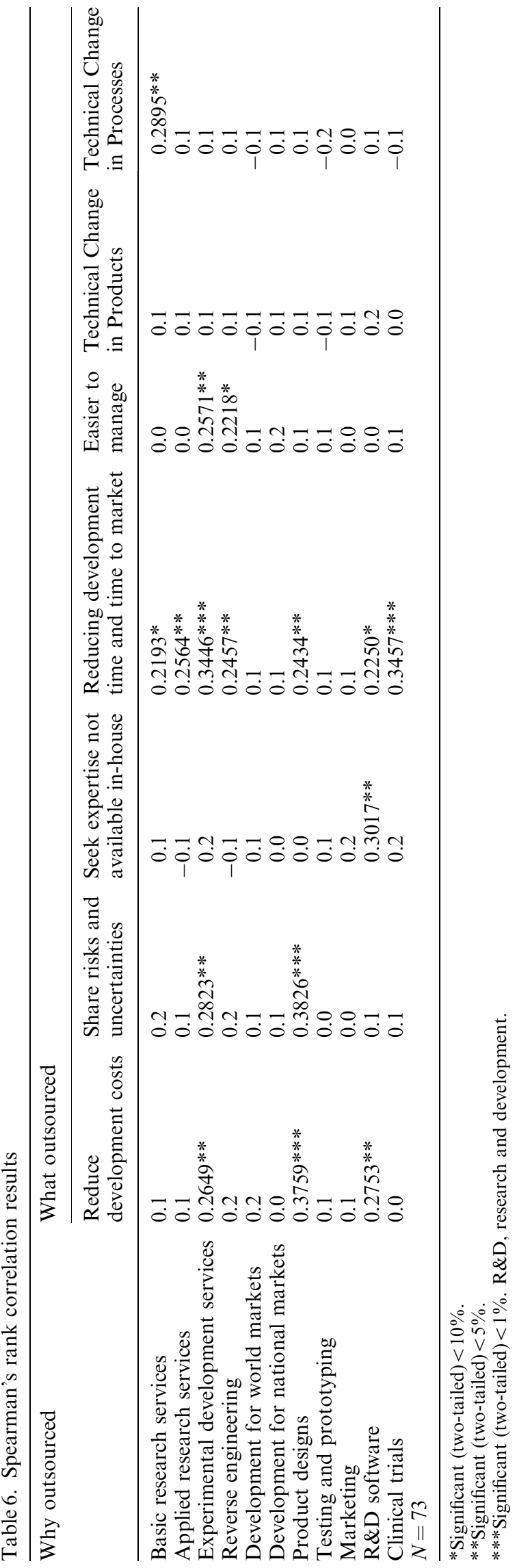

Table 7. Key criteria for partner selection in innovation

\begin{tabular}{lll}
\hline Rank & Criteria for partner selection & Score* $^{*}$ \\
\hline 1 & $\begin{array}{l}\text { Research and technical capability } \\
\text { Ability to get the project done }\end{array}$ & 51 \\
on time & 41 \\
3 & $\begin{array}{l}\text { Ability to be flexible and } \\
\text { cooperative partner }\end{array}$ & 29 \\
4 & $\begin{array}{l}\text { Ability to undertake the project } \\
\text { within cost }\end{array}$ & 27 \\
5 & $\begin{array}{l}\text { General trustworthiness } \\
6\end{array}$ & $\begin{array}{l}\text { Familiarity: worked with them } \\
\text { before }\end{array}$ \\
7 & Other & 15 \\
\hline
\end{tabular}

*Based on ranked scores $(N=70)$.

external expertise in relation to process technology was significantly related to basic R\&D activity $(0.289$ at the $2 \%$ significance level), while risksharing factors were significantly related to product design activity $(0.383$ at the $1 \%$ significance level).

\subsection{Partner selection}

What were the key criteria in partner selection? Not surprisingly, it was the research and technical capability of the partner, but also timeliness in terms of completing the project on time and, to a lesser extent, their flexibility (Table 7). By contrast, ability to undertake the project within cost was rated only fourth, although perhaps this is because most external projects generally have a good track record in meeting cost targets and was therefore not considered a key issue. Trustworthiness and familiarity are also rated generally highly, although this is not surprising, given that the research and drug discovery is a highly uncertain and tacit process where the risks associated with prior disclosure and moral hazard are so high. Indeed, lack of confidence in the potential partner to deliver a relevant solution was rated as the second most important barrier to successful external sourcing of research and technology. By contrast, inability to find a suitable partner was not rated as being a particularly significant barrier to successful outsourcing (Table 7).

\subsection{Barriers to sourcing $R \& D$ and knowledge}

Few studies in relation to $R \& D$ have examined a key management issue relating to outsourcing, namely barriers to the external sourcing of re- 
Table 8. Barriers to external innovation sourcing

\begin{tabular}{|c|c|c|c|}
\hline Rank & Sourcing barrier & $\begin{array}{l}\text { Likert rating } \\
\text { (mean score) }\end{array}$ & $\begin{array}{l}\text { Standard } \\
\text { Deviation }\end{array}$ \\
\hline 1 & $\begin{array}{l}\text { Confidence in the contractor/partner's ability to deliver } \\
\text { relevant solution }\end{array}$ & 3.14 & 1.2628 \\
\hline 2 & $\begin{array}{l}\text { Concern that key knowledge/intellectual property will leak out } \\
\text { to contractor/partner }\end{array}$ & 2.95 & 1.3824 \\
\hline 3 & $\begin{array}{l}\text { Concern that research/technology too central to firm's } \\
\text { competitive advantage }\end{array}$ & 2.39 & 1.3575 \\
\hline 4 & Regulatory restrictions on outsourcing & 2.27 & 1.4243 \\
\hline $5=$ & $\begin{array}{l}\text { Research or technology too difficult to allocate into distinct } \\
\text { activities }\end{array}$ & 2.25 & 1.2539 \\
\hline $5=$ & Could not identify a suitable partner & 2.25 & 1.3846 \\
\hline 7 & $\begin{array}{l}\text { Too much knowledge associated with the project was tacit in } \\
\text { nature }\end{array}$ & 2.18 & 1.2119 \\
\hline 8 & Research and technology too new & 2.16 & 1.2677 \\
\hline 9 & $\begin{array}{l}\mathrm{R} \& \mathrm{D} \text { or technology too difficult to re-absorb back into } \\
\text { business }\end{array}$ & 1.93 & 1.2120 \\
\hline
\end{tabular}

$N=60$.

$\mathrm{R} \& \mathrm{D}$, research and development.

search and technology (Table 8). Using a Likert scale, the issue of barriers to the external sourcing of $R \& D$ was explored in the pharmaceutical industry. On the basis of this evidence, it was found that lack of confidence in the potential partners to deliver a relevant solution to the innovation problem posed by the firm (3.14 on the Likert scale) was seen as the most significant barrier to R\&D outsourcing. This was followed by concern that knowledge and intellectual property would leak out of the firm by collaborating in outsourcing (2.95), which suggests that the need for confidentiality is important in R\&D outsourcing. Confidence and trust about the partner(s), or rather a lack of it, are seen as being major constraints on the sourcing process. The third major barrier (2.39) was associated with concern over the research or technology being considered for outsourcing was too core to the firm's competitive advantage and would be detrimental if the business lost skill and expertise in this area. Given that the pharmaceutical industry is a highly regulated sector, it is not surprising that regulatory restrictions came high up in the rankings (fourth; Table 8) of outsourcing-constraining factors. The next three most significant barriers were: that the research or technology was too difficult to allocate into distinct activities in terms of research modularity; problems over partner selection; and concern that knowledge associated with the project was too tacit in nature, which would restrict the communication and transfer of knowledge and ideas about the project. The last two issues were issues about the newness of the technology and concerns over the ability to re- absorb the research or technology that was generated.

The issues surrounding barriers and constraints to outsourcing highlight the fact that they relate to a variety of different levels and perspectives. Thus, some firms expressed concern over the outsourcing partner $(s)$ involved and their qualities, or lack of them, such as ability and trustworthiness; by contrast, other firms focused on the specific project concerned, for example in relation to its modularity or tacitness, while other firms were concerned with how R\&D outsourcing fitted in with the overall strategy of the firm and the wider institutional environment that the enterprise was posited in.

\section{Conclusions and further directions}

What can be concluded from these findings? A typology of outsourcing factors in relation to research and technology has been presented, centred on initiating and framing factors, which provide a framework for conceptualising the R\&D externalisation process. To this must be added the importance of a variety of different levels and perspectives associated with R\&D outsourcing, which make it a very difficult and complex process to manage. Few studies on outsourcing in relation to R\&D and technical activity have considered these more project-specific issues; rather, they have remained at firm or industry levels for explanation. Yet it is many of the project-level considerations that are seen in this study as being so vital to the survival and growth 
of the firm. This issue clearly needs developing in more detail and is important if we are to satisfactorily describe and conceptualise the whole sourcing for innovation process.

However, the survey also reveals that many of the outsourcing activities linked to $R \& D$ and technical functions in the pharmaceutical industry are associated with more applied activities that are seen as being less strategic, or 'core', to the firm. As shown in Table 5, the enterprises surveyed seem to have focused on the more peripheral, non-core research and technical activities, such as clinical trial activity, R\&D software and applied research, where their external collaborators have more experience and scale and scope benefits. This conclusion is not that straightforward, though, in that basic R\&D activity had a fairly high level of external activity, with its stress on time reduction benefits, but more particularly access to skills in process technology (although product versus process distinctions may now be breaking down in the industry, Lim et al., 2006, p. 34). This latter aspect may, though, merely confirm the view that process technology is seen as being less proprietorial and core to firm's technical competences and therefore it is again seen as a less risky option. It may also revolve around the obvious issues and difficulties associated with R\&D outsourcing that are unlike most other types of outsourcing activities (Section 2), including the high levels of risk and uncertainty, the problem of prior disclosure and information asymmetry, moral hazard and the often unique nature of each $\mathrm{R} \& \mathrm{D}$ outsourcing project that makes learning and the passing on of knowledge about the outsourcing process difficult.

Lastly, more analysis needs to be undertaken on the survey data in particular on the large (pharmaceutical) firm and small (biotechnology) firm relations and how this may provide further insights into the R\&D outsourcing process, but also about wider relations within the industry as a whole. Above all, R\&D outsourcing should not be seen as a minor appendage to the wider outsourcing debate. On the basis of this study, a quarter of all pharmaceutical R\&D expenditure $\left(£ 3,308\right.$ million in $\left.2005^{7}\right)$ is spent externally in Britain; this equates to an estimated market in just one UK sector of $£ 830$ million ( $\$ 1.6$ billion): not a minor sum.

\section{Acknowledgements}

This paper arises from the 'Sourcing for Innovation' project funded by the UK Economic and
Social Research Council (ESRC) through ESRC Centre for Research on Innovation and Competition (CRIC) centre funding (Grant Number ESRC M549285002) and Manchester Business School. An earlier version of this paper was presented at the R\&D Management Conference 'Challenges and Opportunities in $R \& D$ Management: New Directions for Research?' Lake Windermere, 5-7 July 2006. Thanks are due to all the directors and managers involved in the questionnaire survey and case-study interviews and to two anonymous referees for their comments. The views expressed are the authors' alone.

\section{References}

Alchian, A.A. and Demsetz, H. (1972) Production, information costs and economic organization. American Economic Review, 62, 777-795.

Arora, A. and Gambardella, A. (1990) Complementarity and external linkages: the strategies of the large firms in biotechnology. Journal of Industrial Economics, 38, 361-379.

Arrow, K.J. (1962) Economic welfare and the allocation of resources for inventions. In Nelson, R. (ed.), The Rate and Direction of Inventive Activity. Princeton: Princeton University Press, pp. 609-625.

Carter, A.P. (1989) Knowhow trading as economic exchange. Research Policy, 18, 155-163.

Cavusgil, S.T., Calantone, R.J. and Zhao, Y. (2003) Tacit knowledge transfer and firm innovation capability. Journal of Business \& Industrial Marketing, 18, 6-21.

Cohen, W.M. and Levinthal, D.A. (1990) Absorptive capacity: a new perspective on learning and innovation. Administrative Science Quarterly, 35, 128-152.

Coombs, R. (1996) Core competencies and the strategic management of R\&D. $R \& D$ Management, 26, 345-355.

Coombs, R. and Metcalfe, J.S. (2002) Innovation in pharmaceuticals: perspectives on coordination, combination and creation of capabilities. Technology Analysis and Strategic Management, 14, 261-271.

De Laat, P.B. (1999) Dangerous liaisons: sharing knowledge within research and development alliances. In Grandori, A. (ed.), Interfirm Networks: Organization and Industrial Competitiveness. London: Routledge, pp. 208-233.

Della Valle, F. and Gambardella, A. (1993) Biological revolution and strategies for innovation in pharmaceutical companies. $R \& D$ Management, 23, 287-302.

DiMasi, J.A., Hansen, R.W. and Grabowski, H.G. (2003) The price of innovation: new estimates of drug development costs. Journal of Health Economics, 22, 151-185.

Doctor, R.N., Newton, D.P. and Pearson, A. (2001) Managing uncertainty in research and development. Technovation, 21, 79-90. 
Ford, D. and Farmer, D. (1986) Make or buy a key strategic issue. Long Range Planning, 19, 54-62.

Freeman, C. and Soete, L. (1997) The Economics of Industrial Innovation, 3rd edn. London: Pinter.

Galambos, L. and Sturchio, J. (1996) The pharmaceutical industry in the twentieth century: a reappraisal of the sources of innovation. History and Technology, 13, 83-100.

Groenewegen, P. and Wouters, P. (2004) Genomics, ICT and the formation of R\&D networks. Genetics and Society, 23, 167-185.

Hagedoorn, J. (1993) Understanding the rationale of strategic technology partnering: interorganizational modes of cooperation and sectoral differences. Strategic Management Journal, 24, 371-385.

Howells, J. (1996) Tacit knowledge, innovation and technology transfer. Technology Analysis and Strategic Management, 8, 91-106.

Howells, J. (1999) Research and technology outsourcing. Technology Analysis and Strategic Management, 11, 591-603.

Howells, J. (2002) Mind the gap: information and communication technologies, knowledge activities and innovation in the pharmaceutical industry. Technology Analysis and Strategic Management, 14, $335-370$.

Howells, J. (2006) Outsourcing for innovation: systems of innovation and the role of knowledge intermediaries. In Miozzo, M. and Grimshaw, D. (eds.), Knowledge Intensive Business Services: Organizational Forms and National Institutions, Edward Elgar, Cheltenham, pp. 61-81.

Howells, J., James, A. and Malik, K. (2003) The sourcing of technological knowledge: distributed innovation processes and dynamic change. $R \& D$ Management, 33, 395-409.

Howells, J. and Neary, I. (1995) Intervention and Technological Innovation: Government and the Pharmaceutical Industry in the UK and Japan. London: Macmillan.

Jones, O. (2000) Innovation management as a postmodern phenomenon: the outsourcing of pharmaceutical R\&D. British Journal of Management, 11, 341-356.

Liebenau, J.M. (1984) International R\&D in pharmaceutical firms in the early twentieth century. Business History, 26, 329-346.

Lim, P.L.L., Garnsey, E. and Gregory, M. (2006) Product and process innovation in biopharmaceuticals - a new perspective on development. $R \& D$ Management, 36, 27-36.

Lowe, J. and Taylor, P. (1998) R\&D and technology purchase through licence agreements: complementary strategies and complementary assets. $R \& D$ Management, 28, 263-278.

Madhavan, R., Koka, B.R. and Prescott, J.E. (1998) Networks in transition: how industry events (re)shape interfirm relationships. Strategic Management Journal, 19, 439-459.
McKelvey, M. (1995) Evolutionary Innovation: The Business of Biotechnology. Oxford: Oxford University Press.

McKelvey, M., Alm, H. and Riccabani, M. (2001) Does co-location matter? Knowledge collaboration in the Swedish biotechnology-pharmaceutical sector. ESSY Working Paper, Chalmers, Gothenburg.

Mikkola, J.H. (2003) Modularity, component outsourcing, and inter-firm learning. $R \& D$ Management, 33, 439-454.

Mittra, J. (2003) Innovation processes in genomics industry sectors. Innogen Working Paper No. 5, ESRC Centre for Social and Economic Research on Innovation in Genomics, University of Edinburgh.

Mowery, D.C. (1984) Firm structure, government policy, and the organization of industrial research: Great Britain and the United States, 1900-1950. Business History Review, 58, 504-531.

Nelson, R.R. and Winter, S.G. (1982) An Evolutionary Theory of Economic Change. Cambridge, MA: Harvard University Press

Nightingale, P.L. (2000) Economies of scale in experimentation: knowledge and technology in pharmaceutical R\&D. Industrial and Corporate Change, 9, 315-359.

Office for National Statistics (2007) Research and Development in UK Businesses, 2005. Business Monitor (MA14). Norwich: HMSO

Orsenigo, L. (1989) The Emergence of Biotechnology. London: Pinter.

Orsenigo, L., Pammolli, F. and Riccaboni, M. (2001) Technological change and network dynamics: lessons from the pharmaceutical industry. Research Policy, 30, 485-508.

Pisano, G.P. (1994) Knowledge, integration and the locus of learning: an empirical analysis of process development. Strategic Management Journal, 15, 85-100.

Pisano, G.P., Shaw, W. and Teece, D.J. (1988) Joint ventures and collaboration in the biotechnology industry; In Mowery, D.C. (ed.), International Collaborative Ventures in U.S. Manufacturing, Ballinger, Cambridge, MA, pp. 182-222.

Powell, W.W. (1998) Learning from collaboration: knowledge and networks in the biotechnology and pharmaceutical industries. California Management Review, 40, 228-240.

Powell, W.W., Koput, K.K. and Smith-Doerr, L. (1996) Inter-organisational collaboration and the locus of innovation: network learning in biotechnology. Administrative Science Quarterly, 41, 116145

Prahalad, C. and Hamel, G. (1990) The core competence of the corporation. Harvard Business Review, 68, 79-91.

Sanderson, M. (1972) Research and the firm in British industry, 1919-39. Science Studies, 2, 107-151.

Schein, R. and Williams, R. (2002) Chemistry, manufacturing, and controls information in NDAs and 
ANDAs, supplements, Annual Reports, and other regulatory filings. Pharmaceutical Research, 19, 217 226.

Shan, W., Walker, G. and Kogut, B. (1994) Interfirm cooperation and start-up innovation in the biotechnology industry. Strategic Management Journal, 15, 387-394.

Studt, T. (2003) Knowledge management is key to improving drug R\&D cycles. R\&D Magazine April, 18 .

Sutcliffe, K.M. and Zaheer, A. (1998) Uncertainty in the transaction environment: an empirical test. Strategic Management Journal, 19, 1-23.

Thomke, S. and Kuemmerle, W. (2002) Asset accumulation, interdependence and technological change: evidence from pharmaceutical drug discovery. Strategic Management Journal, 23, 619-635.

Walsh, V., Niosi, J. and Mustar, P. (1995) Small-firm formation in biotechnology: a comparison of France, Britain and Canada. Technovation, 15, 303-327.

Welch, J.A. and Nayak, P.R. (1992) Strategic sourcing. Academy of Management Executive, 6, 23-31.

Whittaker, E. and Bower, D.J. (1994) A shift to external alliances for product development in the pharmaceutical industry. $R \& D$ Management, 24, 249-260.

Winter, S. (1987) Knowledge and competence as strategic assets. In Teece, D. (ed.), The Competitive Challenge: Strategies for Industrial Innovation and Renewal, Ballinger, Cambridge, MA, pp. 159-183.

\section{Notes}

1. See 'Accelerating Clinical Trials: Budgets, Patient Recruitment and Productivity' report by Cutting Edge Research Inc., Research Triangle Park, NC, USA (2004).

2. Although there is gradual international harmonisation of drug regulations, national regulatory submissions still remain detailed and wide ranging; see, for example, Howells and Neary (1995), and Schein and Williams (2002).
3. Given that the industry is increasingly international in context, this may appear to be a rather parochial perspective to take on the industry. Apart from the obvious resource limitations of the study, there is also the acknowledged need for studies that move away from the dominance of American data on the industry (an exception is the Pharmaceutical Industry Database covering 4,358 collaborative R\&D projects established by the University of Siena; Orsenigo et al., 2001) and that are based on new databases that are compiled from alternative home country sources that are systematic and provide large-scale material (McKelvey et al., 2001 , p. 28) and that help provide new insights into the drug-development process on an international scale.

4. In this context, the mean spend by the survey enterprises on $R \& D$ outsourcing increased from $£ 84,700$ in 1998 to $£ 167,000$ in 2003 .

5. However, research by Sutcliffe and Zaheer (1998) suggests the reverse, with technological uncertainty leading to a preference for 'arms-length' arrangements.

6. To explore this issue, enterprises were asked simply to indicate whether the following activities: basic research; applied research; experimental development; reverse engineering; world market product development; adapting and developing products for UK market; product design; testing and prototype work; market research and marketing; software used in R\&D; and clinical trial work internally or externally by ticking a box (they could tick both boxes). By counting all responses, the degree of 'externality' could be calculated where 1.00 indicates that the ratio of internal versus external work is equal to below 1.00 where more work is undertaken externally to above 1.00 where the work is more likely to be undertaken internally.

7. Office for National Statistics (2007), p. 11. 


\section{Appendix A}

Table A1. Taxonomy sampling framework of the UK pharmaceutical industry

\begin{tabular}{|c|c|c|c|c|c|c|c|}
\hline Research & Development & $\begin{array}{l}\text { Scaling-up/ } \\
\text { pilot plant }\end{array}$ & Manufacturing & $\begin{array}{l}\text { Marketing } \\
\text { distribution }\end{array}$ & $\begin{array}{l}\text { UK SIC } \\
(2003)\end{array}$ & $\begin{array}{l}\text { Total estimated } \\
\text { population (units) }\end{array}$ & $\begin{array}{l}\text { Sample } \\
\text { (units) }\end{array}$ \\
\hline $\begin{array}{l}X \\
X \\
X \\
X \\
X \\
X \\
X\end{array}$ & $\begin{array}{l}X \\
X \\
X \\
X \\
X \\
X \\
X\end{array}$ & $\begin{array}{l}X \\
X \\
X \\
X \\
X \\
X\end{array}$ & $\begin{array}{l}X \\
X \\
X \\
X \\
X \\
X \\
X\end{array}$ & $\begin{array}{l}X \\
X \\
X\end{array}$ & $\begin{array}{l}73.10 \\
73.10 / 72.2 \\
73.10 / 72.3 \\
24.41 \\
24.41 \\
24.41 \\
24.42 \\
24.42 \\
24.42 \\
24.42 \\
51.46 \\
\text { Total }\end{array}$ & $\begin{array}{r}207 \\
516 \\
(200)^{*} \\
(33)^{*} \\
806\end{array}$ & $\begin{array}{r}35 \\
58 \\
\\
(19) \\
(8) \\
105\end{array}$ \\
\hline
\end{tabular}

Note: ' $\mathrm{X}$ ' shown in Table A1 denotes the activities performed by the business units classified under respective UK SIB (2003). *Excluded from sampling as undertook no R\&D. Total estimated population excluding these units $=806$. How is the pharmaceutical industry defined for the purposes of this study? The pharmaceutical industry in the United Kingdom is classified in a narrow, manufacturing sense, namely Standard Industrial Classification (SIC) 24.4 (UK SIC, 2003), but excluding SIC sub sectors 24.4.3 and 4. However, for completeness new biotechnology firms (NBFs) involved in pharmaceutical research, plus contract research, development and clinical trial companies involved in pharmaceutical work, which are mainly classified under R\&D services SIC classification 73.1 (because they do not undertake any manufacturing), were also included. With developments in the information and knowledge sciences as applied to the pharmaceutical industry, a small number of companies mainly found under UK SIC (2003) codes of 24.4.1 (2) and a secondary code 72.2 (software), 72.3 (data processing) and/or 72.4 (database activities) were included in the survey population if their sole or main activities were in pharmaceutical activity and they undertook R\&D. R\&D, research and development.

Jeremy Howells is a Professor and Executive Director of the Manchester Institute of Innovation Research (MIoIR) and Head of the Innovation Management and Policy (IMP) Division at Manchester Business School, University of Manchester. He received his $\mathrm{PhD}$ from the University of Cambridge. He has published in the International Journal of Technology Management, Prometheus, R\&D Management, Research Policy, Science and Public Policy, Service Industries Journal and Technology Analysis and Strategic Management. His current research interests are on R\&D outsourcing and offshoring, industry-academic links, service innovation and technology transfer. His research has been funded by UK Economic and Social Research Council (ESRC), the Engineering and Physical Sciences Research Council (EPSRC), the European Commission OECD, the European Science Foundation, UNIDO and UNCTAD.

Dr. Khaleel Malik is a Lecturer in Science and Technology Policy and Management at Manchester Institute of Innovation Research
(Manchester Business School) and he has mainly researched in the fields of strategic technology management, knowledge management and innovation policy. He has recently published his research outputs in a number of international journals. Dr. Malik is also the Book Review Editor for the journal $R \& D$ Management.

Dimitri Gagliardi is a researcher at the Manchester Institute of Innovation Research, the University of Manchester. He received his $\mathrm{PhD}$ in Economics and Institution from the University of Bologna. He has been involved in academic positions since 1996. Since 1998, Dr Gagliardi has actively been engaged in economic analysis and applied research, working initially with the Research Institute on the Dynamics of Economic Systems of the Italian Research Council. Dr. Gagliardi worked as a lecturer of Economics of Industry at Leeds University Business School and collaborated with ESRC-CRIC and PREST on various projects. He was awarded a postdoctoral fellowship at the Manchester Business School in 2005. 